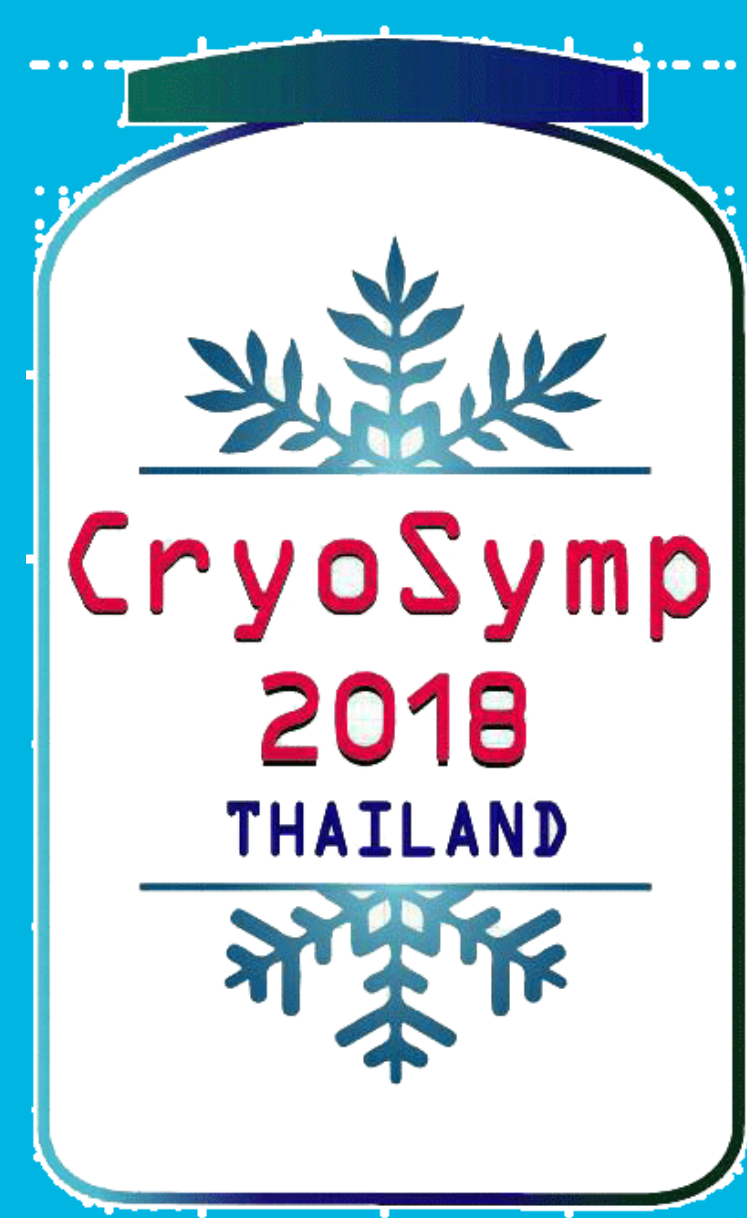

\title{
Modified droplet-vitrification
} cryopreservation of arctic bramble (Rubus arcticus) and hybrid arctic bramble

\author{
Saara Tuohimetsä, Anna Nukari
}

\section{Natural Resources Institute Finland Luke, Horticulture, saara.tuohimetsa@luke.fi}

The goal of the study was to find a modification of dropletvitrification method for valuable Nordic arctic bramble (Rubus arcticus) and hybrid arctic bramble (Rubus a. ssp. $\times$ stellarcticus) and to proceed to the long-term cryopreservation of the mandate variety collections of Rubus at Luke.

\section{Plant material and Methods}

In vitro cultures of the Finnish arctic brambles 'Pima' and 'Susanna' and the Swedish hybrid arctic brambles 'Beata' and 'Sofia' were established from the nuclear plants of certified production (Fig. 1). Cultures were grown at $22^{\circ} \mathrm{C}$ and multiplied at $\sim 6$ week intervals on fructose-based medium containing $0.5 \mathrm{mg} / \mathrm{L}$ BAP and $0.25 \mathrm{mg} / \mathrm{L}$ IBA.

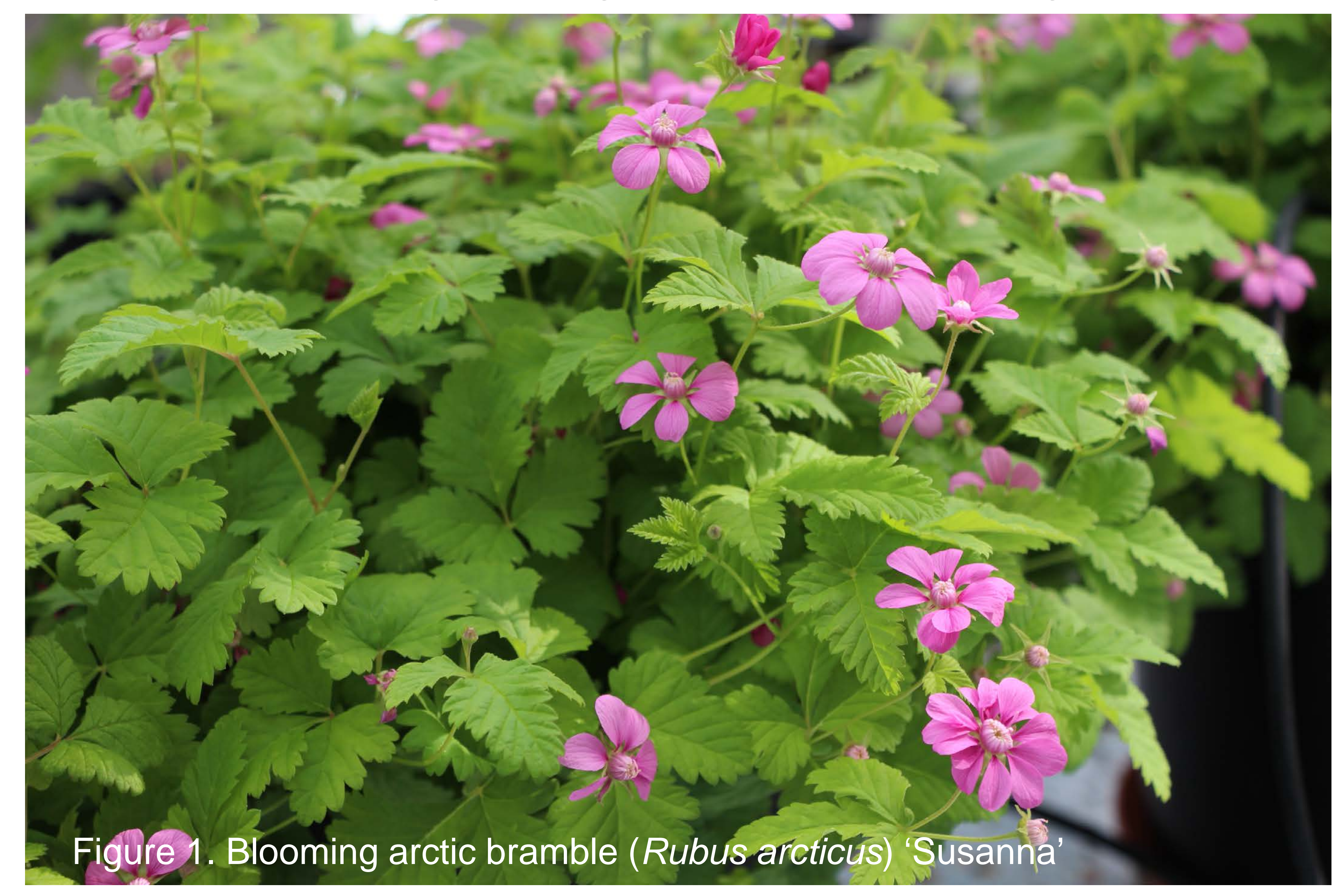

Pretreatment Last multiplication media contained MS mineral salts and vitamins with $0.5 \mathrm{mg} / \mathrm{L}$ BAP, $0.05 \mathrm{mg} / \mathrm{L}$ IBA, $30 \mathrm{~g} / \mathrm{L}$ sucrose, 0.1g/L myo-inositol, pH 5.8. Plants, 3-4 weeks after the last subculture, were cold acclimated (CA) for 1 week at $22^{\circ} \mathrm{C}$ with $8 \mathrm{~h}$ light (50 $\mu \mathrm{E} \times \mathrm{m}-2 \times \mathrm{s}-1) /+4^{\circ} \mathrm{C} 16 \mathrm{~h}$ dark; last two days before apex excision $+4^{\circ}$ C $24 \mathrm{~h}$ dark. Shoot tips and lateral buds (1.5 - $2 \mathrm{~mm}$ ) were excised from CA plants and grown for $24 \mathrm{~h}$ on MS medium containing $0.25 \mathrm{M}$ sucrose and active charcoal following $24 \mathrm{~h}$ on MS medium containing $0.5 \mathrm{M}$ sucrose under the CA conditions.

Vitrification procedure Shoot tips were treated in strainer with loading solution (LS) for $30 \mathrm{~min}$. Strainer was wiped and placed in the cryoprotectant PVS2 (Sakai et al., 1990), held for 30 min altogether. In the end of the PVS2 treatment, 10 shoot tips were placed on aluminum foil strip in three $10 \mu \mathrm{l}$ drops of PVS2. The cryo vials were immersed in liquid nitrogen (LN) and held for minimum 1 hour.

We express our gratitude to the Finnish Ministry of Agriculture and Forestry for financial support. We thank The Nordic Genetic Resource Centre (NordGen) for the support for the preceding cryoprotocol studies on Rubus.
Thawing and regrowth assessment Three vials were thawed ( 2 min water bath at $38^{\circ} \mathrm{C}$ ), and 5-8 vials were long-term preserved (two clonal lines with two repetitions). The shoot tips were rinsed $20 \mathrm{~min}$ in $2 \mathrm{ml}$ liquid $1 \mathrm{M}$ sucrose MS medium. Shoot tips were planted on a solid regeneration medium (in vitro medium described). Recovery showing meristems were transferred onto a fresh medium. Recovery was recorded as survival and regeneration rates.

\section{Results and Discussion}

The results showed survival and regeneration after cryopreservation with all cultivars studied (Table 1, Fig. 2). The two studied hybrid arctic brambles responded to this cryopreservation protocol with higher regeneration rates compared to the two arctic brambles studied. As Reed (2008) highlights that cold acclimation increases the recovery of cryopreserved Rubus meristems, even longer cold acclimation pretreatment might result as higher regenerations.

Table 1. Survival and regeneration rates post LN on studied four Rubus cultivars.

\begin{tabular}{l|c|c|}
\hline Cultivar & $\begin{array}{c}\text { Survival } \\
\text { rate }(\%)\end{array}$ & $\begin{array}{c}\text { Regeneration } \\
\text { rate }(\%)\end{array}$ \\
\hline Susanna & $30 \ldots 40$ & $23 \ldots 40$ \\
\hline Pima & $20 \ldots 40$ & $14 \ldots 40$ \\
\hline Beata & $43 \ldots 53$ & $37 \ldots 50$ \\
\hline Sofia & $40 \ldots 77$ & $33 \ldots 73$
\end{tabular}

Figure 2. Individual
Rubus arcticus 'Pima'
apex has regenerated
into a normal
microplantlet 7,5 week
post LN. All studied
cultivars regenerated with
good quality and formed
dividable cultures post
LN. No excess callus
formation occurred nor
hyperhydricity.

\section{Conclusions}

Studied cryopreservation method was shown applicable for cryopreservation of arctic brambles, and long-term cryopreservation for two clonal lines for each cultivar with two repetitions was performed.

The Rubus cryopreservation studies at Luke will continue with cloudberry (Rubus chamaemorus) to long-term preserve the cloudberry genetic resources. 